\title{
Nontraditional Diplomacy---Chinese Ecological Diplomacy
}

\author{
Jingwei Liu \& Tianyang Sun \\ College of Humanities and Social Sciences \\ Northeast Forestry University \\ Harbin 150040, China
}

Tel: 86-451-8219-2162Ｅ-mail: nefuliujingwei@hotmail.com

\begin{abstract}
From a traditional point of view, a country's diplomatic position and principles are determined by the political environment and military circumstances. The global ecological environment, which has worsened since 1970s, is now paid great attention to by people all over the world. The eco-environmental problem has gradually become one of the most important factors that affect the international relations nowadays. Besides nontraditional diplomacy in culture, trade and security aspects, China is now carving out a new way in nontraditional diplomacy---ecological diplomacy. It greatly impels China to break through the traditional diplomatic thinking and try a new diplomatic strategy.
\end{abstract}

Keywords: Chinese Ecological Diplomacy, Bottleneck, Prospect

\section{The Development of Chinese Ecological Diplomacy}

Since 1960s, people all over the world have attached great importance to the relationship between human and nature. The contamination accident of Guanting Reservoir, which happened in March, 1972, impelled the Chinese government to pay attention to the ecological environment. Three months later, the Chinese Environmental Protection Department contacted with the International Environmental Protection Organization. In June, 1972, the Chinese government organized a big delegation to take part in United Nations Conference on the Human Environment, which was held in Stockholm, the capital of Sweden. This was the first important international conference that China had taken part in since she re-joined the United Nations, which embodied that Premier Zhou Enlai set great store by the environment and international relations. Moreover, it was considered as the beginning of the Chinese ecological diplomacy. The Declaration of Human Environment, which was published in that conference, has an epoch-making significance to the history of human environment movement.

China has been actively taking part in the international discussion on eco-environment since the middle of 1980s. Based on the UN Conference on Environment and Development, some diplomatic activities on ecological problems, such as submit diplomacy, conference diplomacy, treaty diplomacy and expert diplomacy have developed rapidly. China, as well as some developing countries, played an important role in that conference. In the $16^{\text {th }}$ conference of Environmental Protection Committee of State Council, which was held in October, 1989, the Ministry of Foreign Affairs was admitted to the Environmental Protection Committee and participated in the decision-making of foreign environmental policies. The international department and legislation department of the Ministry of Foreign Affairs assigned specialists to take charge of the environmental affairs. What's more, environmental problems were included in the agenda, which embodied that government attached great importance to the environmental foreign affairs.

After 1990, a series of international pacts and documents on environmental problems were published, such as Rio de Janeiro Declaration on Environment and Development, The $21^{\text {st }}$ Century Agenda, Statement on Forest Problems, United Nations Framework Convention on Climate Change, Convention on Biological Diversity, which symbolized that the harmonious development between human and nature had become global common sense.(Zhou, 2007) Especially on the World Environmental Development Conference in 1992, on behalf developing countries, China put her foot down some viewpoints that were put forward by developed countries in the interests of themselves. In the negotiation on Framework Convention on Climate Change, China clearly pointed out that the Responsibility Sharing theory, which was brought forward by the western countries, was unfair and unpractical. The fact is the emission from the developed countries is luxurious, but for the developing countries, that is for survival. China was consistently appraised by the developing countries. More and more developing countries considered China as a reliable friend and it greatly promoted the friendship between China and other developing countries.

In 2008, the Ministry of Environmental Protection was founded. As a flourishing big country, China is now taking more and more responsibility on the global environment. The voice and viewpoints of the Chinese government and academe are of great importance to the world on global eco-environmental problems. 


\section{The Bottleneck of Chinese Ecological Diplomacy}

It has been 30 years since the Reform and Open Policy was published. During this period, China has accomplished fruitful economic achievement, in which the western countries had spent more than 100 years. However, more than 100 years' eco-environmental problems of the western countries were reflected in China's 30 years, too. China's ecological environment is supervised and paid great attention to by the whole world, especially in the bidding process of 2008 Beijing Olympic Games. For all countries, especially the developed countries, as long as they restrict China by means of environmental problems, their candidates will get votes, especially from the left-wing. China's ecological diplomacy are now facing great challenges.

\section{The Chinese Environmental Threat Theory}

As global warming becomes the focus of the whole world, the Chinese Environmental Threat Theory heats up. The so-called Chinese Environmental Threat Theory is that China is the main threat of global warming and will be the biggest greenhouse gas emissions country. Consequently, China must take on responsibility to reduce its greenhouse gas emissions as developed countries. In the developed countries' point of view, population problem and resource consumption problem of the developing countries are the main environmental threats to the international society. For example, the article Who Will Feed China, written by Lester Brown, is a typical ecological threat theory against developing countries. It becomes an important basis for many developed countries and related international organizations to criticize and censure China's ecological problems.

Nevertheless, $15 \%$ of the developed countries' population controls more than $85 \%$ resources of the whole world. Moreover, they carry out ecological colonialism based on their rules. Actually, global warming is the result of greenhouse gas emissions since Industrial Revolution. Undoubtedly, most of the greenhouse gas emission comes from the developed countries. China's greenhouse gas emissions have been gradually increasing since 1980s. That is only a small proportion. Consequently, according to this, it is unfair and unreasonable to require China to take on the corresponding responsibilities and obligations. From another perspective, it is a good way for some developed countries to distract the world's attention and relieve pressure by pushing China to the front and requiring China to take on the same responsibilities in the excuse of economic aggregate and development speed.

\section{Green Barrier}

Green Barrier is the shortened form for Green Trade Barrier (also called Environmental Protection Barrier, Ecological Barrier or Environmental Trade Measures). The definition of Green Barrier is that in the name of protecting ecological environment and human health, a country set discriminatory or unnecessary trade barrier against importation from foreign countries in order to restrict importation and protect trade.(Pan, 2002)

The gap in technology and economic development between developed countries and developing countries is the main factor that impels the green barrier greatly develops. Because of the difference in productivity level, especially on the consideration of both resource protection and economic profits, some environmental and trade contradictions do exist between developed countries and developing countries, which continuously sharpens as the international economic situation develops. Developed countries use this kind of different environmental standards that result from economic level differences in two aspects. On one hand, transfer pollution industries to developing countries while grabbing raw materials from them, which worsens developing countries' environment; on the other, take environmental problems as new trade barriers to set off developing countries' comparative advantage in resource and cheap labor and restrict their economic development to keep leading position in international multilateral economic and trade fields.

Ostensibly, based on some public legislation, such as international convention and laws, Green Barrier complies with sustainable development and human health development. However, exporters can't foresee its contents and changes.

After join in WTO, China, the biggest market, opens its door to the world. And the world market gives opportunities to the Chinese products, too. As a WTO member, China is both a big trade country and an environmental country. Not only should China complies with environmental clauses and specifications, but also accept many international criteria on trade and environment. For now, the majority of the restricted products are from electromechanical and textile industries, but in the future, the automobile industry will be restricted as well. We lost $\$ 31.7$ billion in electromechanical export to Europe only because two environmental protection articles on electro mechanism that were released by EU in 2005, which was $71 \%$ of the total electromechanical export to Europe. Consequently, China's ecological diplomacy takes on great responsibility in trade and environmental problems, but the Green Barrier is too difficult for China to cope with.

\section{Foreign Capital Importation and Independent Development}

What can foreign capital bring us? The introduced environmental protection project may be advanced that what we had before, but it will never be the most advanced. Some environmental protection projects are introduced in order to solve employment problems, but actually, they lag the real environmental protection. As a matter of fact, developed countries have never fulfilled their commitment to transfer environmental protection technology and capital to the developing 
countries. For years, the only thing they have transferred is device, but not the technology. Government always makes an excuse that technology belongs to enterprise itself and enterprise possesses its patent. Domestic enterprises pay out ecological cost and cheap labor, but actually, they only pay pill for the developed countries' environment and resource.

Compared with other countries, we still have great deficiency in environmental protection and the technology of ecological control. Take climate change for example. Various kinds of evaluation reports written by IPCC are playing a more and more important role in international environmental convention activities. However, compared with developed countries, we have fewer experts take part in writing reports and fewer documents are quoted. We don't have strong scientific evidence to protect our countries' interests. As a result, we not only face more pressures in climate change activities, but also in ecological diplomatic activities. Our environmental protection enterprises which possess independent intellectual property and scientific research projects are still in the primary development phase.

\section{Prospect of Chinese Ecological Diplomacy}

The functionality of ecological diplomacy is far more important than political nature. How to protect the domestic resource while taking on a big country's responsibility is the spirit of ecological diplomacy.

\section{Build up Green Image and Promote Soft Power}

Recently, Soft Power is widely accepted and applied in international politics and communication. People domestic and abroad all agree that the improvement of comprehensive national strength should not only be reflected in hard power, such as economy, technology and national defense, but also in soft power, such as policy, culture and ecological environment. The essence of soft power is a country's image and influence. (Huan, 2006, p.147) The stronger the soft power is, the more international influence it will be and vice versa.

\section{Actively Cope with Green Barrier and Create Better Environment}

To break through green trade barrier, developing countries cannot expect that developed countries would willingly help them. They should take part in the international trade and environmental business actively to create better external environment for economy and trade. Moreover, developing countries need to actively cope with various kinds of trade barriers to strengthen their power in international trade negotiation and resist being imposed country system and policies.

Currently, ecological diplomacy has been an important means for the developed countries to expand green trade. In the international trade and cooperative ecological diplomacy, China should take on positive measures, expand green industries, improve the quality of green products and break through the green barrier to guarantee that our green products can successfully come into the international market. What's more, we need to gain the initiative, make research for international trade and environmental management and fully use diplomatic means to counterattack various kinds of green trade barriers.

\section{Widen Capital and Technical Channel, Encourage Independent Development}

China is a big manufacturing country, but not a strong manufacturing country. Many products in the world are based on the biggest world factory---China. The high consumption of resource and energy leads to our energy deficiency and environmental pollution. The National Science and Technology Support Plan, which was published in February, 2007, brought forward to transform 'Made in China' to 'Green Manufacturing' by putting the 'Key Technology and Equipment of Green Manufacturing' project into effect.

The 'Key Technology and Equipment of Green Manufacturing' project requires us to reduce the resource consumption and environmental pollution to break through the international green trade barrier. Moreover, we need to put forward a set of key technology and equipment for green manufacturing products and actualize some demonstration projects to improve our green manufacturing ability and the proportion of products and technology of independent intellectual property.

Up to the end of 2007, China has already had more than 1000 environmental cooperative projects with UN and other international organizations. What's more, science and technology cooperation, technical transfer and various kinds of environmental projects and research have been implemented between China and a great number of countries, which play a key role in widening the channel to introduce foreign capital and technology and encouraging independent development of environmental protection enterprises.

\section{Conclusion}

The functionality of China's ecological diplomacy is far more important than its political nature. On one hand, China cannot banish the international moral justice to develop. This will greatly damage her image. On the other, China should not abandon her rights to develop, too. As the biggest developing country, China greatly impels the whole world to develop with her. China's ecological diplomacy should not only protect her own development benefits in the negotiation on international environmental conventions to guarantee the long-term development strategic to be successfully 
implemented, but also make contribution to the global environmental protection.

We should make clear the purpose of joining in the international organizations. China's ecological diplomacy should not only make good use of international rules, but also resist unreasonable international ecological system and create new mechanism and rules.

The research on China's ecological diplomacy theory and ecological environment still has a long way to go. Ecological diplomacy theory must be based on absorbing the advantage of developed countries' related theories and considering China's condition to guarantee China's leading position in the ecological diplomacy. Meanwhile, we should make more research on the statistics of ecological environment to gain initiative in the process of ecological diplomacy, actively participate in multilateral negotiation on ecological environment, especially on the global climate change, to get ready for the new round negotiation to safeguard China's development rights and interests.

\section{References}

Huan Qingzhi, (2006). International Comparisons on Environmental Politics Jinan: Shandong University Press. P.147
Pan
Haiping,
(2002).
Green
Barriers.
[Online]
Available:

http://news.xinhuanet.com/fortune/2002-04/17/content_361465.htm (July 7, 2007).

Zhou Shengxian, (2007). Build an ecological civilization. People's Daily. 24 December 2007. 